\title{
Nurmen kasvumallin kehitys kainuulaisella aineistolla
}

\author{
Ulla Sihto ${ }^{1)}$ ja Marketta Rinne ${ }^{2)}$ \\ ${ }^{1)}$ MTT (Maa- ja elintarviketalouden tutkimuskeskus), Kotieläintuotannon tutkimus, Kipinäntie 16, \\ 88600 Sotkamo, ulla.sihto@mtt.fi \\ ${ }^{2)}$ MTT (Maa- ja elintarviketalouden tutkimuskeskus), Kotieläintuotannon tutkimus, 31600 Jokioi- \\ nen, marketta.rinne@mtt.fi
}

\section{Tiivistelmä}

Korjuun ajoittaminen on yksi tärkeimpiä karjatilan rehuntuotantoon vaikuttavia päätöksiä, koska tarpeettoman aikainen korjuu pienentää sadon määrää ja korjuun myöhentäminen vähentää lehmien maidontuotantoa ja/tai vaatii suuremman väkirehutäydennyksen. Artturi Korjuuaikatiedotuksen ennustamat D-arvot eivät ole Kainuussa aina vastanneet nurminäytteiden analyysien tuloksia. MTT Sotkamoon perustettiin satokausiksi 2006-2007 kehittämishankkeet "Nurmen korjuuajan määrittäminen Kainuun olosuhteissa” ja "Nurmen korjuuaika Kainuussa”.

Nurminäytteitä kerättiin vuonna 2006120 kpl ja vuonna 2007160 kpl. Ensimmäisen vuoden nurmilohkot valittiin kuuden kunnan alueelta siten, että pääsääntöisesti jokaisesta kunnasta valittiin yksi turve- ja yksi kivennäismaalohko. Toisen vuoden nurmilohiksi valittiin vain kivennäismaita seitsemästä kunnasta kahdeksalta tilalta kaksi nurmilohkoa kultakin tilalta mahdollisimman suurella korkeuserolla. Lohkoilta kerättiin näytteitä kesän ensimmäisessä ja toisessa sadossa n. 5 kpl/sato viikon välein kasvuston kehityksen selvittämiseksi.

Nurmikasvustojen D-arvo laski alkukesällä 0.45 ja loppukesällä 0.19 \%-yksikköä päivässä. Lämpösumman yhteys D-arvoon oli selkeä erityisesti 1. sadossa. D-arvon vaihtelu oli 2. sadossa vähäisempää kuin 1. sadossa. Vuoden 2006 tulosten regressioanalyysin mukaan kylmillä turvemailla D-arvo oli 1 . sadossa $0.98 \%$-yksikköä korkeampi ja 2. sadossa $0.73 \%$-yksikköä matalampi kuin lämpimillä mailla. Vuonna 2007 D-arvot olivat 1. sadossa korkeilla lohkoilla keskimäärin 0.7 \%-yksikköä ja 2. sadossa 0.5 \%-yksikköä korkeampia kuin matalilla lohkoilla.

D-arvon ennustamisessa kannattaisi ottaa yhä enemmän huomioon tilakohtaiset tekijät kuten maalajit, korkeuserot, kasvilajit, lannoitus, korjuupäivä sekä sademäärä. Tulosten analysointi ja käsittely jatkuvat, ja aineistoa hyödynnetään Artturi Korjuuaikatiedotuksen D-arvoennustemallien päivityksessä keväällä 2008.

\section{Asiasanat:}

Nurmirehu, sulavuus, korjuuaika, maalaji, kivennäismaa, turvemaa, D-arvo, kasvupaikka, korkeus 


\section{Johdanto}

Nurmikasvien kehitys alkukesällä on erittäin nopeaa. Sadon määrä kasvaa, mutta samalla kasvimassan sulavuus laskee (Rinne 2000, Rinne ym. 2007). Nurmirehun sulavuus vaikuttaa merkittävästi siihen, kuinka paljon lehmät syövät rehua (Rinne ym. 2008) ja tuottavat maitoa (Rinne ja Huhtanen 2006). Korjuun ajoittaminen on yksi tärkeimpiä karjatilan rehuntuotantoon vaikuttavia päätöksiä, koska tarpeettoman aikainen korjuu pienentää sadon määrää ja korjuun myöhentäminen vähentää lehmien maidontuotantoa ja/tai vaatii suuremman väkirehutäydennyksen.

Artturi-verkkopalvelun (Artturi 2007) Korjuuaikatiedotus esittää alkukesällä päivittäin ennusteet nurmiheinien ja apilan D-arvosta. Ennusteet perustuvat nurmen kasvumalliin, jossa lämpösumman ja kasvupaikan perusteella empiirisellä regressioyhtälöllä ennustetaan D-arvo (sulavan orgaanisen aineen pitoisuus kuiva-aineessa). Viljelijät ovat kokeneet palvelun tarpeelliseksi, sillä kesäkuussa 2007 verkkosivuilla rekisteröitiin 26000 käyntiä ja 103000 sivujen näyttökertaa (Google Analytics). Verkkopalvelu on maksuton eikä vaadi rekisteröitymistä. D-arvohälytys on mahdollista tilata myös maksullisena tekstiviestinä matkapuhelimeen.

Artturi Korjuuaikatiedotuksen ennustamat D-arvot eivät ole Kainuussa aina vastanneet nurminäytteiden analyysien tuloksia. Poikkeamia on ollut molempiin suuntiin, mutta useimmiten Artturi on ennustanut nurmen olevan vanhempaa kuin se tosiasiassa on ollut. Mahdollisina virhetekijöinä on epäilty Kainuun suuria korkeuseroja ja maalajien vaihtelua.

MTT Sotkamoon perustettiin satokausiksi 2006-2007 kehittämishankkeet "Nurmen korjuuajan määrittäminen Kainuun olosuhteissa” ja "Nurmen korjuuaika Kainuussa”. Näytteistä saatiin runsaasti materiaalia nurmen kasvumallin kehitykseen, joka hyödyttää sekä Kainuuta että koko Suomea. Samalla kerättiin aineistoa nurmen jälkisadon kehityksestä, josta ei vielä ole käytettävissä ennustemallia.

Nämä hankkeet olivat Kainuun TE-keskuksen rahoittamia EU-hankkeita (EMOTR), joita rahoittivat myös Kajaanin ja Kuhmon kaupungit, Hyrynsalmen, Paltamon, Sotkamon, Suomussalmen ja Vaalan kunnat sekä MTK Kainuu, MTK Sotkamo, Kainuun maaseudun tuki ja Sotkamon manttaalisäätiö.

\section{Aineisto ja menetelmät}

Ensimmäisenä koevuonna 2006 valittiin keväällä Kainuun maakunnasta maitotiloilta 12 maantieteellisesti edustavaa nurmilohkoa, joilta kerättiin korjuuaikanäytteet ensimmäisestä ja toisesta sadosta, 4-6 näytettä kultakin lohkolta. Koelohkoiksi valittiin kivennäis- ja turvemaita vaara- ja tasamailta. Kauimmaisten lohkojen etäisyys oli 167 km, korkein lohko 283 m ja matalin 119 m merenpinnan yläpuolella.

Toisena koevuonna 2007 nurmilohkoja valittiin 16 kpl. Koelohkoiksi valittiin ainoastaan kivennäismaita ja valintakriteerinä oli kahden lohkon mahdollisimman lyhyt etäisyys toisistaan ja samalla mahdollisimman suuri korkeusero. Näin pyrittiin saamaan ensimmäistä koevuotta paremmin esiin mahdollinen korkeuden vaikutus nurmen kasvumalliin. Käytännössä kahdeksalta tilalta valittiin kultakin 2 lohkoa jotka täyttivät kriteerit parhaiten. Kauimmaisten lohkoparien etäisyys oli 112 kilometriä, matalin lohko oli $127 \mathrm{~m}$ ja korkein lohko 316 m merenpinnan yläpuolella.

Koelohkojen nurmet olivat toisen, kolmannen tai joissain tapauksissa myös neljännen vuoden nurmia. Kainuussa nurmi perustetaan usein ilman suojaviljaa syksyllä. Nurmet olivat timotei-, timotei-nurminata- tai timotei-ruokonatakasvustoja. Lajikkeina olivat timoteillä Iki, Tuukka, Tammisto ja Jonathan, nurminadalla Salten ja Kasper sekä ruokonadalla Retu. Typpilannoitusta käytettiin $100 \mathrm{~kg} / \mathrm{ha} / \mathrm{sato}$

Näytteiden keruu koelohkoilta aloitettiin noin kahta viikkoa ennen ensimmäisen sadon arvioitua korjuuajankohtaa. Näytteet kerättiin jokaiselta lohkolta kerran viikossa viitenä peräkkäisenä viikkona siten että mukaan tuli yleensä kaksi näytettä korjuuajankohdan jälkeen. Näytteenotto toistettiin samanlaisena myös toisessa sadossa. Näin joka koelohkolta otettiin noin 10 korjuuaikanäytettä kultakin. Näytteet otettiin kehikkomenetelmällä siten, että joka lohkolta otettiin vähintään neljä $0.25 \mathrm{~m}^{2}$ osanäytettä. Kun näyte punnittiin, pystyttiin laskemaan nurmen hehtaarisato. Näytteenoton yhteydessä mitattiin myös kasvuston korkeus. Lämpötila- ja sadesummat kullekin korjuupäivälle ja -paikalle saatiin Ilmatieteen laitoksen ns. hila-aineistosta eli ne on laskettu useiden sääasemien tuloksista $10 \times 10 \mathrm{~km}$ ruuduille. 
Kustakin saadusta korjuuaikanäytteestä valmistettiin kaksi rinnakkaisnäytettä. Ensimmäinen näyte kuljetettiin Valion Lapinlahden rehulaboratorioon (v. 2006) tai Valion Seinäjoen rehulaboratorioon (v. 2007), jossa se analysoitiin välittömästi lähi-infrapuna- eli NIR-menetelmällä [raakavalkuainen (RV), kuitu (neutraalidetergenttikuitu) ja D-arvo]. Tulokset julkaistiin heti niiden valmistuttua Artturi-verkkopalvelussa ja tulokset olivat siten viljelijöiden käytettävissä korjuun ajoittamisen tukena.

Toisesta näytteestä määritettiin MTT Sotkamossa primäärinen kuiva-aine, $\left(105{ }^{\circ} \mathrm{C}\right)$. Muita analyysejä varten kuivattiin näyte $+60{ }^{\circ} \mathrm{C}$-asteeessa. Nämä kuivatut näytteet analysoitiin MTT:n laboratoriossa. Niistä määritettiin RV, kuitu ja sulamaton kuitu (12 pv pötsi-inkubaatio nailonpusseissa). Koska kaikki MTT:n tulokset eivät vielä ole valmistuneet, tämän kirjoituksen tarkastelussa on käytetty Valion NIR-analyysien tuloksia.

Nurmen kehitystä kasvun edetessä tarkasteltiin sekamalli-regressioanalyysillä (SAS MIXED -proseduuri), jossa yhdestä kasvustosta kerättyä sarjaa käytettiin satunnaistekijänä. Mallien sopivuutta arvioitiin jäännösvaihtelun (residual mean squared error, RMSE) ja selitysasteen (Adj. $\mathrm{R}^{2}$ ) avulla.

\section{Tulokset ja tulosten tarkastelu}

Nurminäytteitä kerättiin vuonna 2006120 kpl ja vuonna 2007160 kpl. Ensimmäisen vuoden nurmilohkot valittiin kuuden kunnan alueelta siten, että pääsääntöisesti jokaisesta kunnasta valittiin yksi turve- ja yksi kivennäismaalohko. Samassa kunnassa sijaitsevien lohkojen välillä oli korkeuseroa 10 - 89 m. Samasta kunnasta näytteet otettiin samana päivänä, jolloin lohkojen näytteiden analyysitiedot olivat keskenään vertailukelpoisia näytepäivän suhteen.

Toisen vuoden nurmilohiksi valittiin vain kivennäismaita seitsemästä kunnasta kahdeksalta tilalta kaksi nurmilohkoa kultakin tilalta mahdollisimman suurella korkeuserolla. Suurin lohkojen välinen korkeusero oli 101 metriä ja pienin 10 metriä. Samalta tilalta näytteet otettiin samana päivänä, jolloin lohkoparin näytteiden analyysitiedot olivat keskenään vertailukelpoisia näytepäivän suhteen.

Aineiston kuvailu on esitetty taulukossa 1 . Näytteiden tulokset vaihtelivat huomattavasti johtuen siitä, että kasvustoja seurattiin pitkän ajan. Näin ne antavat myös hyvän mahdollisuuden tarkastella kasvuolosuhteiden ja rehun laadun yhteyttä. Näytteiden sulavuuden sekä RV- ja kuitupitoisuuden vaihtelu oli hieman vähäisempää toisessa sadossa ensimmäiseen satoon verrattuna. Tässä aineistossa D-arvon keskiarvo oli sama molemmissa sadoissa (70.6 ja 70.3 \%), mutta RV-pitoisuus oli hieman suurempi ja kuitupitoisuus pienempi jälkisadossa.

Kuvassa 1 molempien vuosien näytteiden D-arvot on esitetty sadoittain. Kuvista näkyy, että D-arvon lasku on 1. sadossa nopeampaa kuin 2. sadossa. Myös lohkojen väliset tasoerot ovat 1. sadossa pienempiä kuin loppukesällä. Vuonna 2006 satojen välinen ero oli selkeämpi kuin v. 2007.

Taulukko 1. Nurmiaineiston kasvuolosuhteiden ja ominaisuuksien kuvailu.

\begin{tabular}{|c|c|c|c|c|c|c|c|c|}
\hline & \multicolumn{4}{|c|}{ Ensimmäinen sato $(\mathrm{n}=125)$} & \multicolumn{4}{|c|}{ Toinen sato $(\mathrm{n}=139)$} \\
\hline & $\mathrm{X}$ & s.d. & Min. & Max. & $\mathrm{X}$ & s.d. & Min. & Max. \\
\hline Kasvupaikan kork., m & 198 & 51.9 & 119 & 316 & 197 & 51.6 & 119 & 316 \\
\hline Pv toukokuun alusta & 50.0 & 9.13 & 34 & 64 & & & & \\
\hline Pv kasvun alusta ${ }^{1)}$ & 46.6 & 12.44 & 23 & 71 & 43.9 & 11.63 & 20 & 72 \\
\hline Lämpösumma, C & 309 & 190.7 & 118 & 1242 & 670 & 255.3 & 242 & 1721 \\
\hline Sadesumma, mm & 82.4 & 32.52 & 10 & 175.9 & 134. & 84.38 & 23.9 & 281.7 \\
\hline Kasvuston kork., cm & 60.2 & 17.40 & 25 & 98 & 47.8 & 13.03 & 19 & 77 \\
\hline Sato, kg KA/ha & 4325 & 1923 & 500 & 9200 & 2597 & 1240 & 500 & 6000 \\
\hline D-arvo, \% & 70.6 & 4.76 & 60.2 & 77.8 & 70.3 & 3.28 & 63.4 & 77.0 \\
\hline RV-pitoisuus, \% & 16.8 & 5.40 & 7.9 & 31.8 & 18.2 & 4.60 & 10.7 & 30.3 \\
\hline Kuitupitoisuus, \% & 54.0 & 7.01 & 39.5 & 66.0 & 50.9 & 5.71 & 37.8 & 62.4 \\
\hline $\begin{array}{l}\mathrm{X}=\text { keskiarvo } \\
\text { Min. = minimi }\end{array}$ & $\begin{array}{l}\text { s.d. } \\
\text { Ma }\end{array}$ & $\mathrm{Sh}$ & & & & & & \\
\hline
\end{tabular}



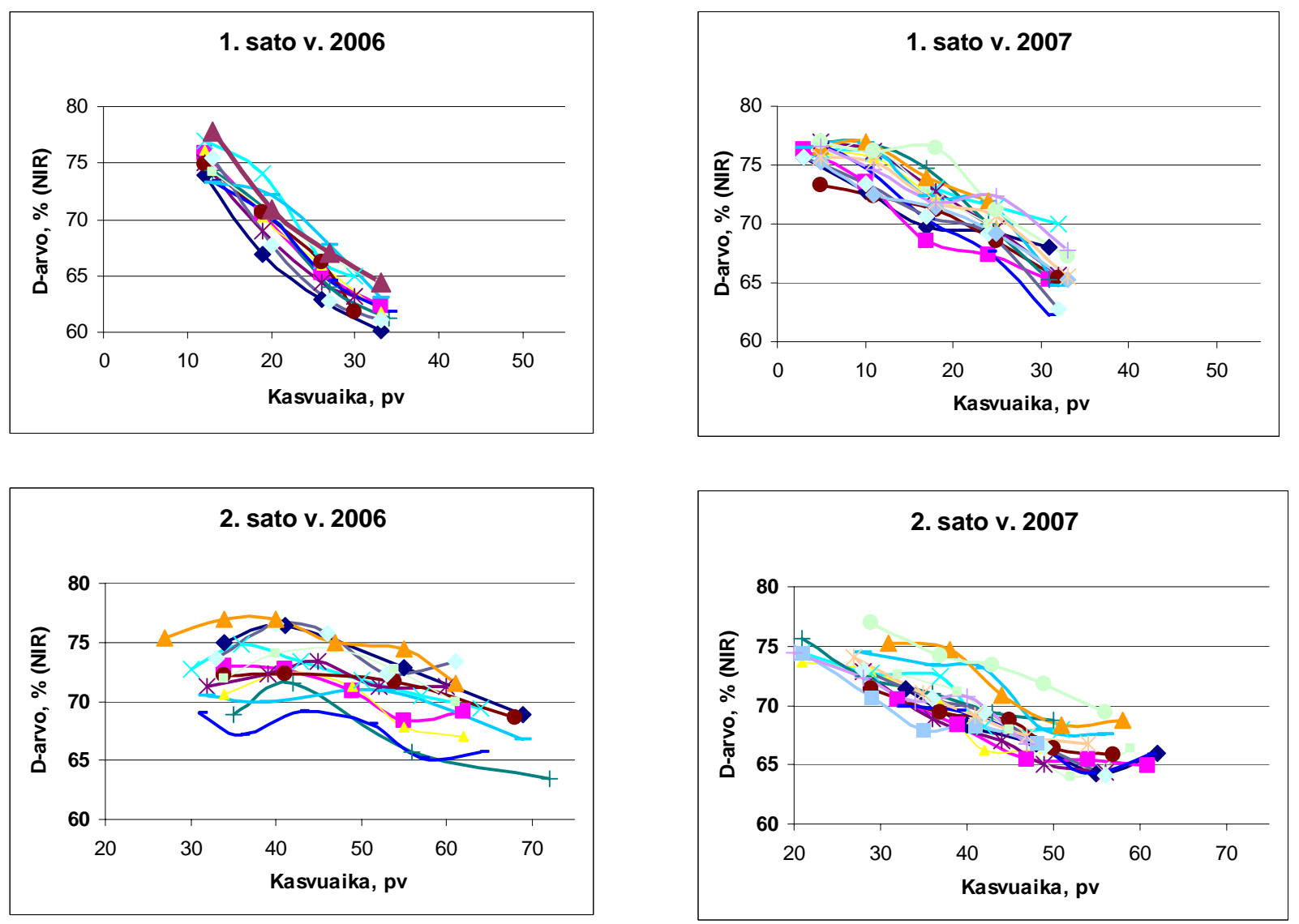

Kuva 1. Nurmiheinien D-arvon muutos kasvun edetessä 1. ja 2. sadossa vuosina 2006 ja 2007.

Samasta kasvustosta otetut näytteet on yhdistetty viivalla. Kuvissa on käytetty samoja mittaasteikkoja, joten satojen erot hahmottuvat silmämääräisesti. Kasvuaika ensimmäisessä sadossa on laskettu kesäkuun alusta ja toisessa sadossa 1. sadon korjuusta.

Taulukko 2. Nurmikasvustojen D-arvon (\%) ennustaminen regressiomallilla kasvuolosuhteiden perusteella. Tilastollisesti merkitsevät $(\mathrm{P}>0.05)$ kulmakertoimet on lihavoitu.

\begin{tabular}{cccccccccc}
\hline $\begin{array}{c}\text { Teki- } \\
\text { jä 1 }\end{array}$ & $\begin{array}{c}\text { Teki- } \\
\text { jä 2 }\end{array}$ & $\begin{array}{c}\text { Teki- } \\
\text { jä 3 }\end{array}$ & $\begin{array}{c}\text { Sa- } \\
\text { to }\end{array}$ & Vakio & $\begin{array}{c}\text { Kulma- } \\
\text { kerroin 1 }\end{array}$ & $\begin{array}{c}\text { Kulma- } \\
\text { kerroin 2 }\end{array}$ & $\begin{array}{c}\text { Kulma- } \\
\text { kerroin 3 }\end{array}$ & Virhe & $\begin{array}{c}\text { Adj. } \\
\mathrm{R}^{2}\end{array}$ \\
\hline Pv & & & 1 & 93.0 & $\mathbf{- 0 . 4 4 9}$ & & & 1.65 & 0.860 \\
& & & 2 & 78.7 & $\mathbf{- 0 . 1 8 6}$ & & & 1.33 & 0.728 \\
LS & & & 1 & 84.5 & $\mathbf{- 0 . 0 4 5}$ & & & 1.78 & 0.959 \\
& & & 2 & 76.3 & $\mathbf{- 0 . 0 0 9}$ & & & 1.88 & 0.592 \\
LS & \multirow{2}{*}{ kork } & & 1 & 75.5 & $\mathbf{- 0 . 0 4 5}$ & $\mathbf{0 . 0 4 6}$ & & 1.79 & 0.958 \\
& & & 2 & 72.2 & $\mathbf{- 0 . 0 0 9}$ & $\mathbf{0 . 0 2 1}$ & & 1.89 & 0.610 \\
LS & \multirow{2}{*}{ mlaji } & & $1^{\text {b) }}$ & 86.5 & $\mathbf{- 0 . 0 5 2}$ & $\mathbf{- 0 . 9 7 6}$ & & 1.00 & 0.961 \\
& & & $2^{\text {b) }}$ & 77.2 & $\mathbf{- 0 . 0 1 3}$ & $\mathbf{0 . 7 2 9}$ & & 1.24 & 0.648 \\
LS & \multirow{2}{*}{ kork } & \multirow{2}{*}{ mlaji } & 1 & 77.7 & $\mathbf{- 0 . 0 4 6}$ & $\mathbf{0 . 0 4 4}$ & $\mathbf{- 1 . 7 4}$ & 1.80 & 0.958 \\
& & & 2 & 71.4 & $\mathbf{- 0 . 0 0 9}$ & $\mathbf{0 . 0 2 1}$ & 0.578 & 1.89 & 0.620 \\
LS & \multirow{2}{*}{ kork } & \multirow{2}{*}{ mlaji } & $1^{\text {b) }}$ & 89.1 & $\mathbf{- 0 . 0 5 2}$ & $\mathbf{- 0 . 0 1 3}$ & $\mathbf{- 1 . 0 0}$ & 1.01 & 0.962 \\
& & & $2^{\text {b) }}$ & 73.5 & $\mathbf{- 0 . 0 1 3}$ & $\mathbf{0 . 0 1 9}$ & $\mathbf{0 . 7 5}$ & 1.25 & 0.756 \\
\hline
\end{tabular}

${ }^{\text {a) Mallin jäännösvaihtelu (residual mean squared error) }}$

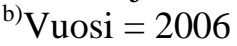

$\mathrm{Pv}=1$. sadossa päiviä toukokuun alusta, 2. sadossa päiviä 1. sadon korjuusta

LS = lämpösumma, $\mathrm{C}^{\circ}$

kork = kasvupaikan korkeus merenpinnasta, $\mathrm{m}$

mlaji = maalaji luokiteltuna lämpimiin (1) ja kylmiin (2) 
Vuonna 2006 selvitettiin 6 lohkoparin avulla maalajin vaikutusta D-arvon kehitykseen. Maalajit luokiteltiin kylmiin (turvemaat) ja lämpimiin (kivennäismaat). Lohkojen kaikkien näytteiden $(\mathrm{n}=5)$ keskiarvoja verrattiin toisiinsa. Keskimäärin D-arvot olivat 1. sadossa kylmillä mailla 0.2 \%yksikköä matalampia ja 2. sadossa 0.7 \%-yksikköä korkeampia kuin lämpimillä mailla (kuva 2). Vaikutukset olivat siis melko vähäisiä, mutta maalajin vaikutus oli merkitsevä regressioanalyysissä (taulukko 2). Vuoden 2006 tulosten regressioanalyysin mukaan kylmillä turvemailla D-arvo oli 1. sadossa 0.98 \%-yksikköä korkeampi ja 2. sadossa 0.73 \%-yksikköä matalampi kuin lämpimillä mailla.

Vuonna 2007 näyteaineistoksi valittiin 8 tilalta 2 nurmilohkoa, joiden korkeusero oli mahdollisimman suuri. Keskimäärin D-arvot olivat 1. sadossa korkeilla lohkoilla 0.7 \%-yksikköä ja 2. sadossa 0.5 \%-yksikköä korkeampia kuin matalilla lohkoilla (kuva 3). Ero oli myös merkitsevä regressioanalyysissä (taulukko 2).

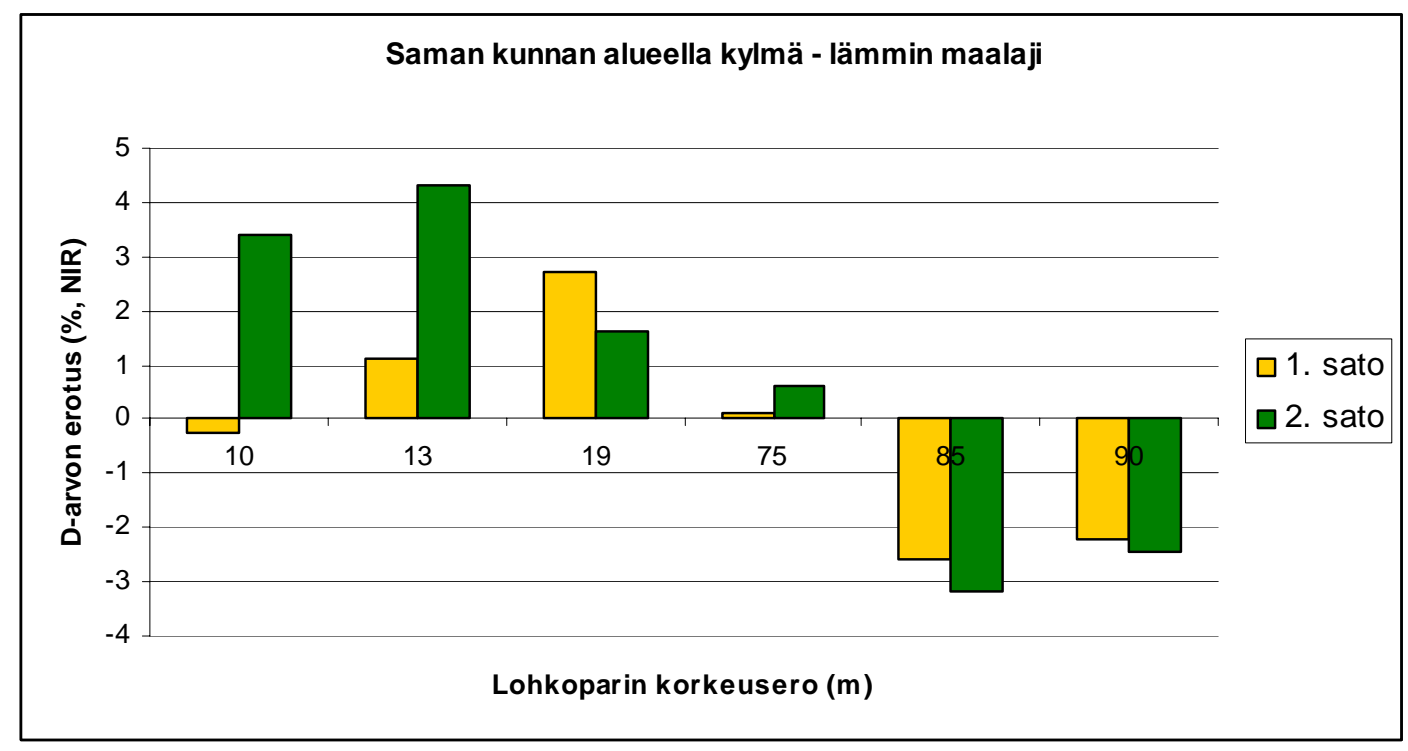

Kuva 2. Vuonna 2006 saman kunnan alueelta otettujen kylmän (turvemaa) ja lämpimän (kivennäismaa) lohkon D-arvojen erotus. Kuvaan on laitettu näkyviin lohkojen korkeusero siten että se kasvaa vasemmalta oikealle.

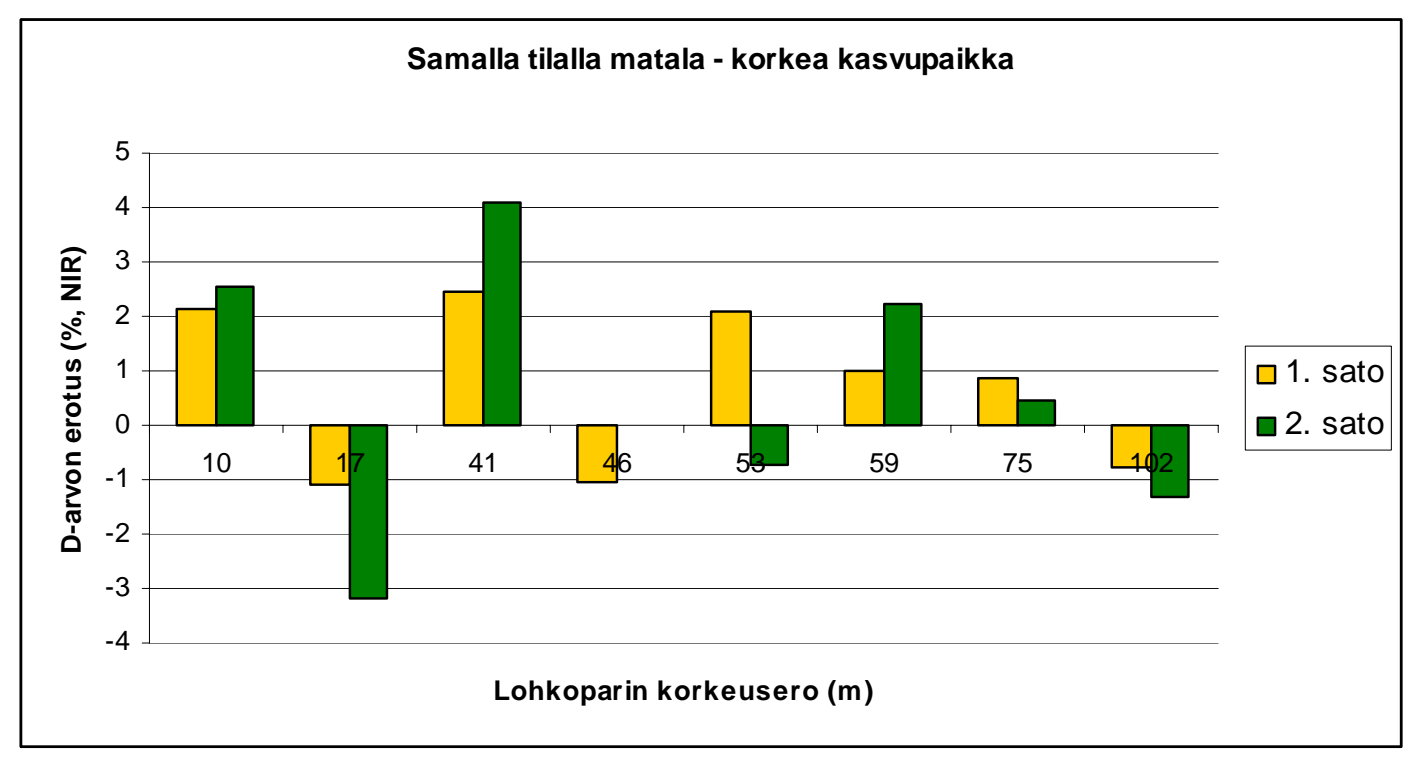

Kuva 3. Vuonna 2007 samalta tilalta otettujen matalan ja korkean lohkon D-arvojen erotus. Kuvaan on laitettu näkyviin lohkojen korkeusero siten että se kasvaa vasemmalta oikealle. 
Nurmikasvustojen D-arvo laski alkukesällä 0.45 ja loppukesällä 0.19 \%-yksikköä päivässä. Lämpösumman yhteys D-arvoon oli selkeä erityisesti 1. sadossa. D-arvon vaihtelu oli 2. sadossa vähäisempää kuin 1. sadossa, joten vaikka mallien selitysasteet $\left(R^{2}\right)$ olivat huonompia, oli jäännösvaihtelu (RMSE) 2. sadon malleissa pienempi. Kasvupaikan korkeuden ja maalajin vaikutukset olivat regressioanalyysissä merkitseviä, mutta niiden huomioiminen ei merkittävästi pienentänyt Darvoennustemallien jäännösvaihtelua.

Tässä aineistossa on mukana 2 vuotta. Vuosien väliset erot kasvuolosuhteissa ovat usein suuria. Ensimmäisenä kesänä v. 2006 kuivuus vaivasi etenkin toista satoa ja toisena kesänä taas sademäärät olivat keskimääräistä suurempia. Etenkin kuivuus vaikutti D-arvon kehitykseen siten, että se pysyi kuivilla lohkoilla koko ajan korkealla tasolla eikä laskenut ollenkaan alle 70 prosentin. Darvon ennustamisessa kannattaisi ottaa yhä enemmän huomioon tilakohtaiset tekijät kuten maalajit, korkeuserot, kasvilajit, lannoitus, korjuupäivä sekä sademäärä. Tulosten analysointi ja käsittely jatkuvat, ja aineistoa hyödynnetään Artturi Korjuuaikatiedotuksen D-arvoennustemallien päivityksessä keväällä 2008.

\section{Johtopäätökset}

Nurmikasvustojen D-arvo laski alkukesällä 0.45 ja loppukesällä 0.19 \%-yksikköä päivässä. Lämpösumman yhteys D-arvoon oli selkeä erityisesti 1. sadossa. Arturi-verkkopalvelun Korjuuaikatiedotuksen D-arvoennusteet perustuvat tähän yhteyteen (www.mtt.fi/artturi). Tutkimuksessa maalajin ja kasvupaikan korkeuden vaikutukset D-arvoon olivat merkitseviä. D-arvon ennustamisessa kannattaisi ottaa yhä enemmän huomioon tilakohtaiset tekijät kuten maalajit, korkeuserot, kasvilajit, lannoitus, korjuupäivä sekä sademäärä. Tulosten analysointi ja käsittely jatkuvat, ja aineistoa hyödynnetään Artturi Korjuuaikatiedotuksen D-arvoennustemallien päivityksessä keväällä 2008.

\section{Kirjallisuus}

Artturi, 2007. Artturi -verkkopalvelu. Viitattu 30.11.2007. Saatavilla: www.mtt.fi/artturi.

Rinne, M. 2000. Influence of the timing of the harvest of primary grass growth on herbage quality and subsequent digestion and performance in the ruminant animal. University of Helsinki, Department of Animal Science. Publications 54. 42 p. +5 encl. Academic dissertation. Available at:

http://ethesis.helsinki.fi/julkaisut/maa/kotie/vk/rinne.

Rinne, M. \& Huhtanen, P. 2006. Paljonko maitoa saa tonnista rehuviljaa? ProAgria Maito -valmennus, Vantaa 24.8.2006. Saatavilla: https://portal.mtt.fi/portal/page/portal/Artturi/Artturikirjasto/Artturikoulutus /ProAgria\%20Maito\%20valmennus\%202006\%20\%20Koulutusmateriaali/Marketta\%20Rinne\%202006.pdf

Rinne, M., Huhtanen, P., Aura, E., Tirkkonen, L., Nousiainen, J., Hellämäki, M., Mattila, I., Nikander, H., Virkajärvi, P., Isolahti, M. \& Järvenranta, K. 2002. Nurmen korjuuajan optimoiminen kasvumallien avulla. Nurmen kilpailukyvyn parantaminen - tutkimusohjelman päätösseminaari, Oulunsalo 18.4.2002. Suomen Nurmiyhdistyksen julkaisu nro 17. Toim. O. Niemeläinen \& M. Topi-Hulmi. pp. 29-43.

Rinne, M., Nykänen, A., Nyholm, L., Nousiainen, J. \& Vanhatalo, A. 2007. Kehitysrytmi huomioitava api-lanurmen korjuussa. Puna-apilaa nurmiin ja ruokintapöydälle. Puna-apila tehokkaasti luomumaidoksi tutkimushankkeen päätösseminaari 17.4.2007. Toim. A. Vanhatalo \& M. Topi-Hulmi Suomen Nurmiyhdistyk-sen julkaisuja 25: 23-33. Saatavilla Internetissä:

https://portal.mtt.fi/portal/page/portal/AGRONET/HTML/NURMIYHDISTYS/sisallysluettelot/rinne.pdf

Rinne, M., Huhtanen P. \& Nousiainen, J. 2008. Säilörehun ja koko rehuannoksen syönti-indeksit auttavat lypsylehmien ruokinnan suunnittelussa. Maataloustieteen Päivät 2008. 